\title{
The synergic antitumor effects of paclitaxel and temozolomide co-loaded in mPEG-PLGA nanoparticles on glioblastoma cells
}

\author{
Yuanyuan $\mathrm{Xu}^{1, *}$, Ming Shen ${ }^{1, *}$, Yiming $\mathrm{Li}^{2}$, Ying Sun ${ }^{1}$, Yanwei Teng ${ }^{1}$, Yi Wang ${ }^{2}$, \\ Yourong Duan ${ }^{1}$ \\ ${ }^{1}$ State Key Laboratory of Oncogenes and Related Genes, Shanghai Cancer Institute, Renji Hospital, School of Medicine, \\ Shanghai Jiao Tong University, Shanghai 200032, P. R. China \\ ${ }^{2}$ Department of Ultrasound, Huashan Hospital, School of Medicine, Fudan University, Shanghai 200040, P. R. China \\ *These authors have contributed equally to this work \\ Correspondence to: Yourong Duan, e-mail: yrduan@shsci.org \\ Yi Wang, e-mail: y_wang1111@hotmail.com \\ Keywords: nanoparticles, synergy, glioblastoma, paclitaxel, temozolomide \\ Received: November 12, $2015 \quad$ Accepted: February 20, $2016 \quad$ Published: March 03, 2016
}

\section{ABSTRACT}

To get better chemotherapy efficacy, the optimal synergic effect of Paclitaxel (PTX) and Temozolomide (TMZ) on glioblastoma cells lines was investigated. A dual drug-loaded delivery system based on mPEG-PLGA nanoparticles (NPs) was developed to potentiate chemotherapy efficacy for glioblastoma. PTX/TMZ-NPs were prepared with double emulsification solvent evaporation method and exhibited a relatively uniform diameter of $206.3 \pm 14.7 \mathrm{~nm}$. The NPs showed sustained release character. Cytotoxicity assays showed the best synergistic effects were achieved when the weight ratios of PTX to TMZ were $1: 5$ and $1: 100$ on U87 and C6 cells, respectively. PTX/TMZ-NPs showed better inhibition effect to U87 and $\mathrm{C} 6$ cells than single drug NPs or free drugs mixture. PTX/TMZ-NPs (PTX: TMZ was 1:5(w/w)) significantly inhibited the tumor growth in the subcutaneous $U 87$ mice model. These results indicate that coordinate administration of PTX and TMZ combined with NPs is an efficient method for glioblastoma.

\section{INTRODUCTION}

Glioblastoma (GBM) is the most common and aggressive primary brain tumor $[1,2]$ with median survivals only $12-15$ months $[3,4]$. The treatment is still worldwide challenging. Given the post-operative radiotherapy could not prevent its recurrence and invasiveness towards surrounding brain tissue, the National Comprehensive Cancer Network (NCCN) 2012 suggested that patients with glioblastoma should consider chemotherapy except for with pilocytic astrocytoma or newly diagnosed ependymocytoma. The present treatment of GBM is multimodal involving surgery, radiotherapy and chemotherapy [5].

Temozolomide (TMZ) is the first agent in 20 years approved by the FDA to treat glioblastoma and has been one of the most commonly used anti-glioma agents with limited adverse effects $[6,7]$ due to its ability penetrating the blood brain barrier (BBB). The standard treatment is maximal surgical resection and maintenance treatment with temozolomide (TMZ), which could improve median and 5-year survival significantly [8]. However, the therapeutic effects of TMZ are far less enough. The O6-methylguanine-DNA methyltransferase (MGMT), a DNA repair protein involved in the resistance of tumor cells to alkylating agents, is also expressed in glioblastoma and contributes to the resistance to TMZ [9-11]. Thereby, combinational administrations of TMZ with other chemotherapeutics have been under study for improving the efficacy of glioblastoma therapies [12].

Paclitaxel (PTX) plays a crucial role in various tumors, as a kind of anti-microtubule drug. It has been the first-line therapy for patients with breast cancer and non-small cell lung carcinoma $[13,14]$. PTX was reported a good apoptosis-inducing effect for glioblastoma cells in vitro $[15,16]$. Moreover, the penetrating ability into the brain tumors of PTX was at least two orders of magnitude greater than carmustine and 5-fluorouracil, etc. [17].

Given TMZ belongs to cell cycle non-specific drugs, while PTX is a cell cycle specific drug which 
could restrain cell cycle at $\mathrm{G} 2 / \mathrm{M}$, we hypothesized that TMZ and PTX might exhibit synergistic effects if co-delivered simultaneously. One study indicated that PTX in combination with an alkylating agent could synergistically inhibit numerous types of cancers [18]. Particularly, PTX combined with cisplatin or TMZ has clear synergistic inhibitory effects against malignant glioblastoma cells in vitro [19]. But there were few reports on the optimal weight ratios of the two drugs co-delivered. Furthermore, the water solubility of PTX or TMZ is a serious limitation [20, 20]. Appropriate strategies were needed to co-deliver these two drugs effectively to brain. Among the multiple approaches, polymeric NPs seem to possess many advantages such as increased drugs reaching tumor sites, enhanced selectivity and the potential to co-deliver multiple agents simultaneously.

In this research, we prepared our nanoparticles with monomethoxy (polyethylene glycol) - poly (D, L-lactideco-glycolide) (mPEG-PLGA). PLGA was approved for medical applications by FDA as a biocompatible and biodegradable polymer [21-23]. The mPEG could help the nanoparticles escape from reticuloendothelial system phagocytose and prolong its circulation in the bloodstream and further increase nanoparticles accumulation at the tumor tissues through the EPR effect [24-26]. We first determined the optimal weight ratio of PTX to TMZ for the composite nanoparticles delivery system. Then the dual drug-loaded mPEG-PLGA NPs was prepared with a double emulsion solvent evaporation method. The characteristics of the nanoparticles and their cytotoxicity

(A)
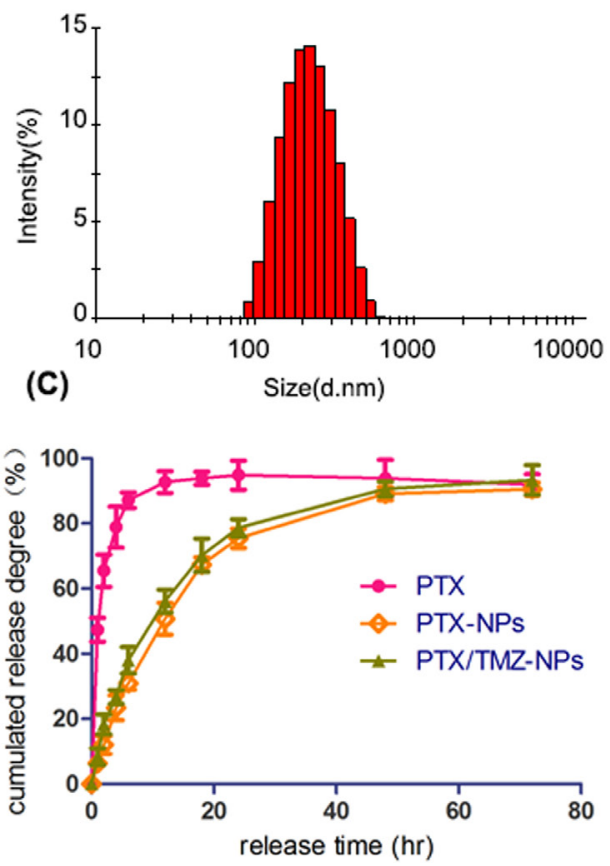

profiles on U87 human malignant glioblastoma cells and C6 rat glioma cells were accessed. In vivo anti-tumor activity was evaluated with a BALB/c subcutaneous U87 glioblastoma xenograft model.

\section{RESULTS}

\section{Characteristics of PTX/ TMZ-NPs}

The mean size of PTX-NPs was $154.9 \pm 21.3 \mathrm{~nm}$ prepared by the emulsion solvent evaporation method. TMZ-NPs and PTX/TMZ-NPs, prepared with the double emulsion solvent evaporation technique, achieved an average diameter of $172.9 \pm 10.9 \mathrm{~nm}$ and $206.3 \pm 14.7$ $\mathrm{nm}$ (Figure 1A), respectively. The PTX/TMZ-NPs had a relatively smooth surface and uniform morphology (Figure 1B). The DL and EE of the NPs were listed in Table 1.

The accumulated amount of PTX released from PTX solution achieved the maximum at $20 \mathrm{~h}$, while from PTX-NPs or PTX/TMZ-NPs were both near $80 \mathrm{~h}$ (Figure 1C), showing apparent sustained characteristic and no significant difference between the two nanoparticles groups. Similarly, The TMZ released from the TMZNPs and PTX/TMZ-NPs showed remarkable sustained feature comparing with TMZ solution (Figure 1D). We could concluded that drugs-loaded nanoparticles exhibited a sustained release feature with decreasing amount of initial release, which might be explained by that drugs were gradually released with the dissolution of polymers.

(B)

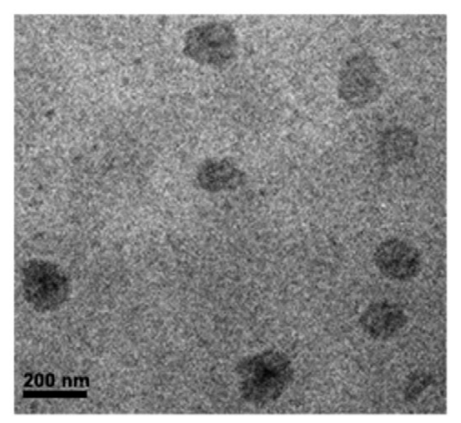

(D)

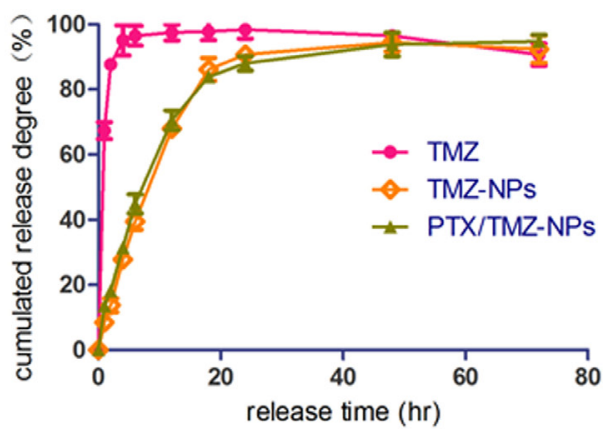

Figure 1: Characteristics of PTX/TMZ-NPs. A. Particle size of PTX/TMZ-NPs. B. TEM image of PTX/TMZ-NPs. C. The PTX release profile. D. The TMZ release profile. 
Table 1: The DL and EE of drug loaded NPs

\begin{tabular}{lcc}
\hline NPs & DL \% & EE \% \\
\hline PTX-NPs & 0.917 & 92.5 \\
TMZ-NPs & 3.14 & 64.5 \\
PTX/TMZ-NPs (PTX) & 0.871 & 90.7 \\
PTX/TMZ-NPs (TMZ) & 3.15 & 65.2 \\
\hline
\end{tabular}

\section{Synergic inhibition of PTX and TMZ on U87 cells and $\mathrm{C} 6$ cells}

As expected, both PTX and TMZ demonstrated concentration-dependent inhibitory effects on U87 cells and $\mathrm{C} 6$ cells in vitro by MTT assay. The $\mathrm{IC}_{50}$ of PTX and TMZ for U87 cells at $48 \mathrm{~h}$ were $4.5 \mathrm{mg} / \mathrm{L}$ and $77.3 \mathrm{mg} / \mathrm{L}$, respectively. C6 cell line was more sensitive to both the two drugs. The $\mathrm{IC}_{50}$ values of PTX and TMZ for C6 cells were $0.1 \mathrm{mg} / \mathrm{L}$ and $28.0 \mathrm{mg} / \mathrm{L}$, respectively.

To investigate the synergistic inhibitory effects of PTX and TMZ, both drugs at different concentrations were used to simultaneously treat cells based on the $\mathrm{IC}_{50}$ values. The results showed that TMZ increased the cytotoxicity of PTX on U87 (Figure 2) and C6 cells (Figure 3). CDI values were all less than 1 , which meant PTX and TMZ had synergistic effects on both U87 cells and C6 cells.

The combination of PTX and TMZ on the concentrations of $4.0 \mathrm{mg} / \mathrm{L}$ and $20 \mathrm{mg} / \mathrm{L}$, respectively showed a better synergic effect (lower CDI values) on U87 cells. We speculated that when the ratio of PTX to TMZ was $1: 5(\mathrm{w} / \mathrm{w})$ the synergic effect on U87 was the best. While the most remarkable synergic effect was observed on $\mathrm{C} 6$ cells when the concentrations were $0.05 \mathrm{mg} / \mathrm{L}$ and $5 \mathrm{mg} / \mathrm{L}$, respectively. Therefore, the best synergic effect on C6 was obtained when the ratio of PTX to TMZ was $1: 100(\mathrm{w} / \mathrm{w})$. Nevertheless, increasing the concentrations of PTX or TMZ further did not yield statistically significant differences in CDI values.

\section{Combined inhibitory and apoptosis-inducing effects of PTX and TMZ co-loaded in MPEG- PLGA NPs on U87 cells and C6 cells}

Figure 4 indicated that the combined formulations, including the PTX/TMZ, Mix-NPs or PTX/TMZ-NPs, all presented synergic effects when incubated with U87 cells and C6 cells, respectively. PTX/TMZ-NPs exhibited a better synergic effect with statistically significant differences comparing with Mix-NPs. Nevertheless, PTX/TMZ-NPs showed significant differences to PTX/ TMZ formulations only at $48 \mathrm{~h}$ and $72 \mathrm{~h}$, but not at 24 $\mathrm{h}$, which may be in accordance with the sustained release characteristic of NPs. The blank mPEG-PLGA NPs did not have any cytotoxic effects on the both cells.
Significantly different apoptotic rates were observed among various treatments at $48 \mathrm{~h}$ on U87 cells and C6 cells (Figure 5). Exactly as the proliferation inhibitory results demonstrated that statistically significant differences not only existed between single and dual drug groups, but also among the combined formulations groups, wherein the apoptosis rate of PTX/TMZ-NPs group was the highest.

\section{In vivo anti-tumor efficacy of PTX/TMZ-NPs}

In vivo anti-tumor efficacy of PTX/TMZ-NPs was evaluated on the subcutaneous U87 model. As shown in Figure 6, the tumor sizes of therapeutic groups were all notably smaller than that of the control group $(\mathrm{P}<0.01)$. The inhibition effect of PTX/TMZ-NPs was the best. We also found that effects of dual drug groups were better than single drug groups, whatever in solution or in nanoparticles. The nanoparticles groups were better than PTX/TMZ solution but without significant difference. These results were in the same trend with the results in vitro.

However, the significant loss of whole body weight was observed in PTX or PTX/TMZ group indicating systemic toxicity (Figure 6B), which was coincident with other reports $(23,40)$. However, this did not happen in NPs groups. We hypothesized that the sustained release and tumor target of the NPs reduced the side-effects.

\section{DISCUSSION}

Combination therapy is a common way of clinical oncology chemotherapy. Because the TMZ and PTX produce the antitumor effect by different routes, we were interested in their combined effect on tumor. In addition, the two drugs are of water soluble and fat soluble separately and their encapsulation in NPs can be achieved by a same method and should not affect each other. It was reported that glioma cells exhibit decreased glucose uptake and lactate production in response to treatment with TMZ; however, glucose metabolism was increased after Taxol treatment. And the glucose metabolism was decreased in the TMZ-resistant cells, but was increased in the Taxol-resistant cells (41). This might be a performance of synergy. The combination therapy of the two drugs were reported good effect in a phase I trial on melanoma (42). 

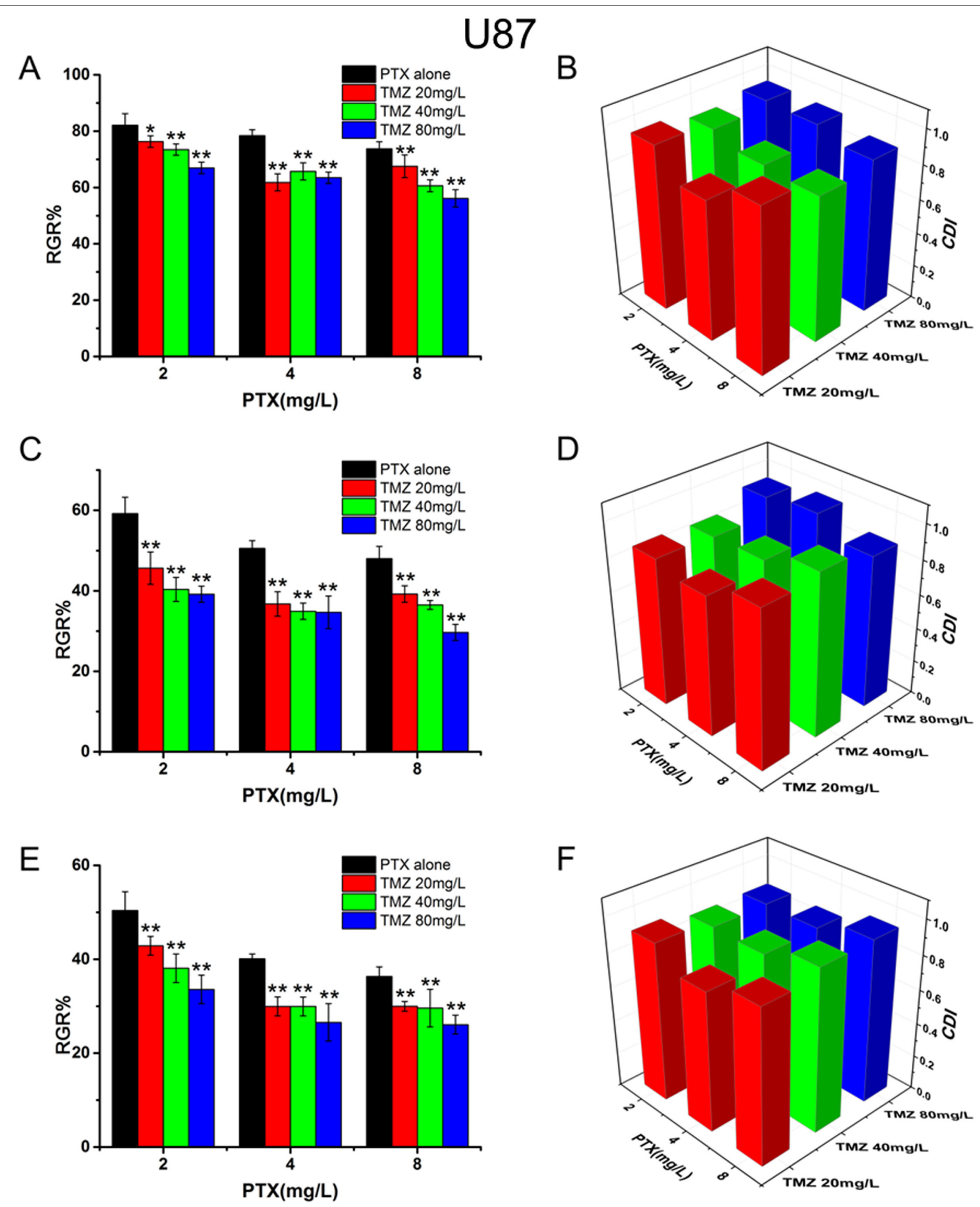

Figure 2: The synergistic inhibitory effects and CDI values of PTX and TMZ for U87 cells. U87 cells treated with PTX and TMZ for $24 \mathrm{~h} \mathrm{A.} 48 \mathrm{~h}$ C. $72 \mathrm{~h} \mathrm{E}$. CDI values of the combination groups for U87 cells for $24 \mathrm{~h} \mathrm{B.} 48 \mathrm{~h}$ D. $72 \mathrm{~h} \mathrm{~F}$. Data are presented as mean \pm S.D. (error bar) of triplicate cultures. ${ }^{*} \mathrm{P}<0.05,{ }^{*} \mathrm{P}<0.01$, vs. PTX alone. 

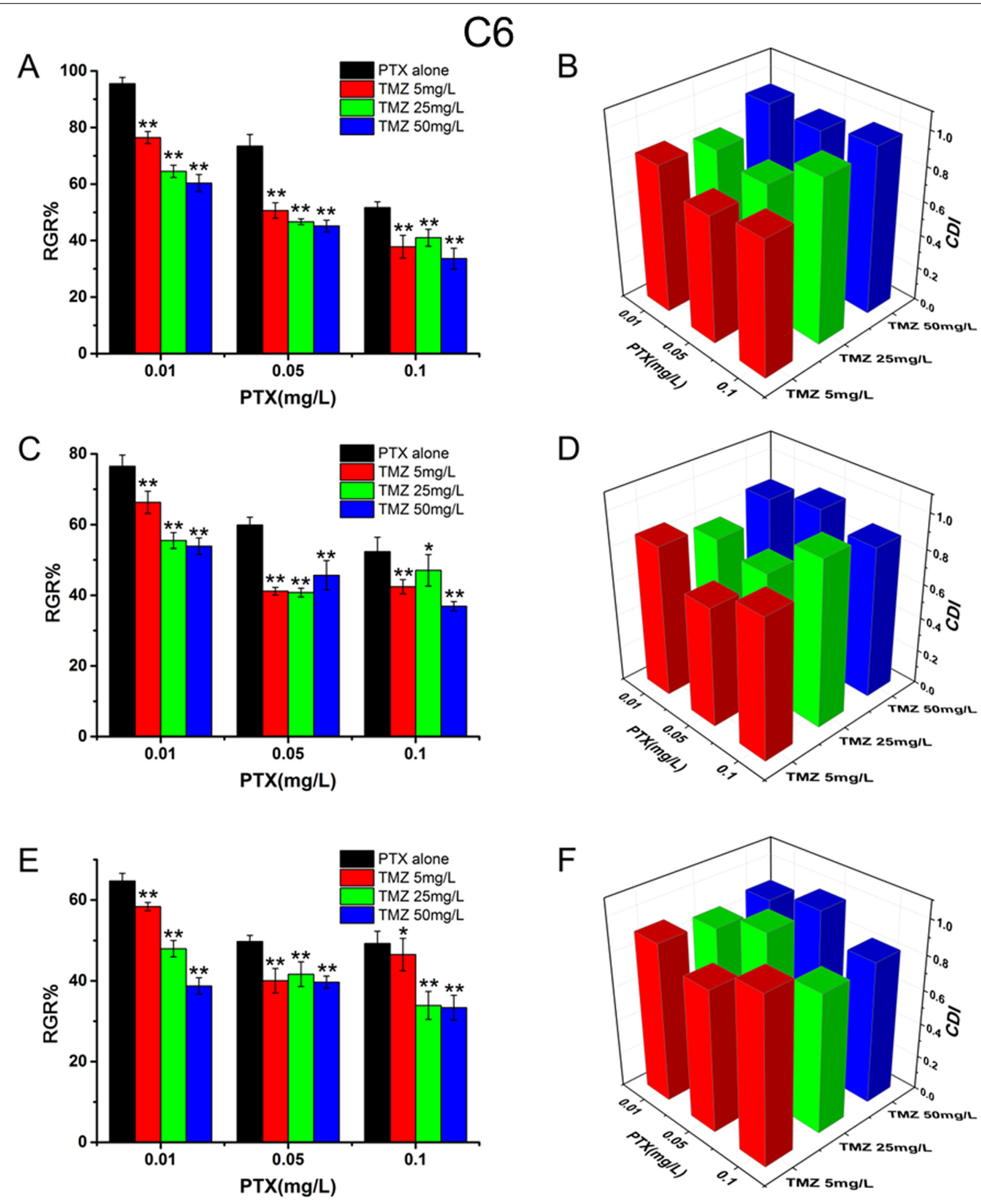

Figure 3: The synergistic inhibitory effects and CDI values of PTX and TMZ for C6 cells. C6 cells treated with PTX and TMZ for 24 h A. 48 h C. 72 h E. CDI values of the combination groups for C6 cells for 24 h B. 48 h D. 72 h F. Data are presented as mean \pm S.D. (error bar) of triplicate cultures. $* \mathrm{P}<0.05$, $* * \mathrm{P}<0.01$, vs. PTX alone. 

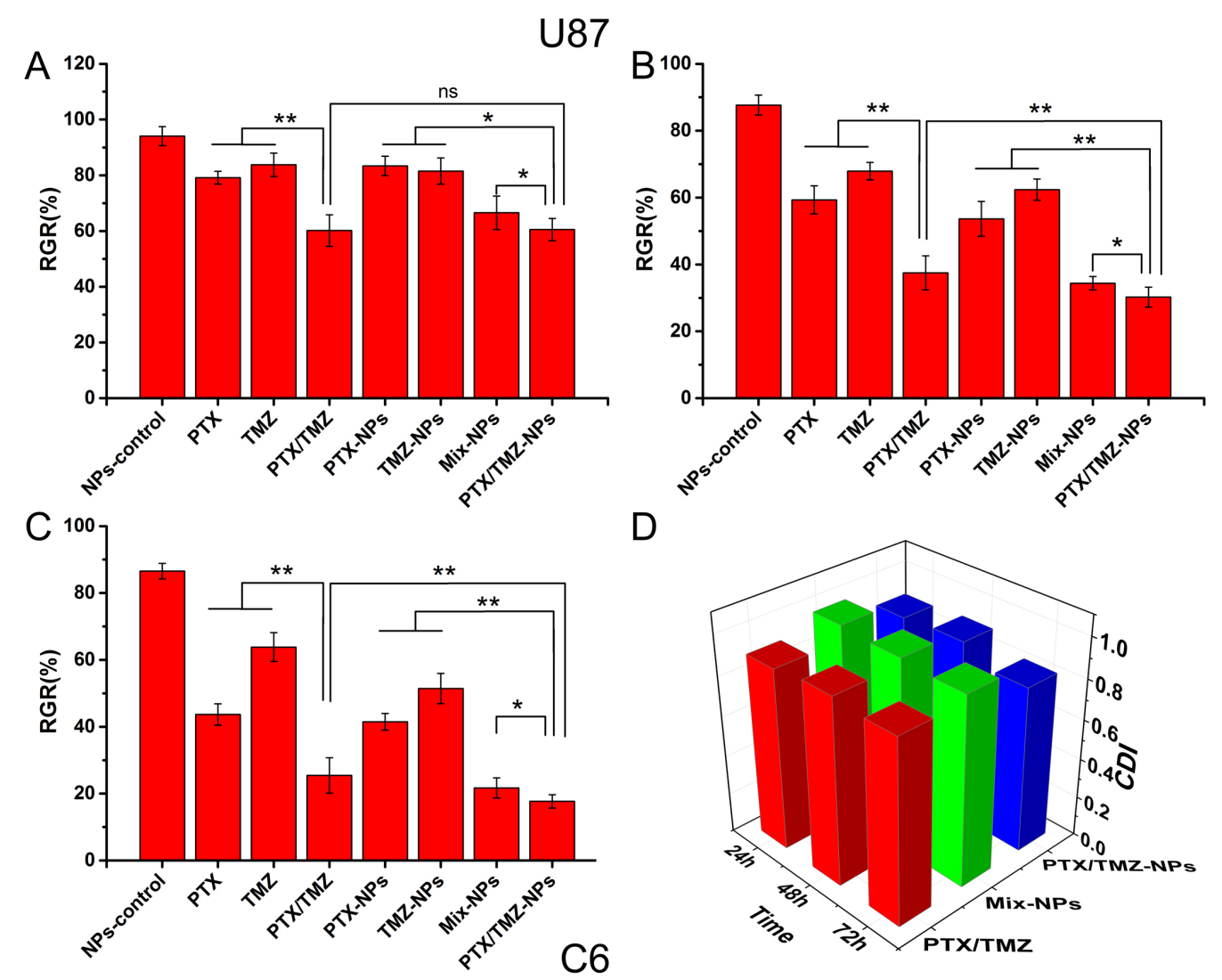

$\mathrm{D}$
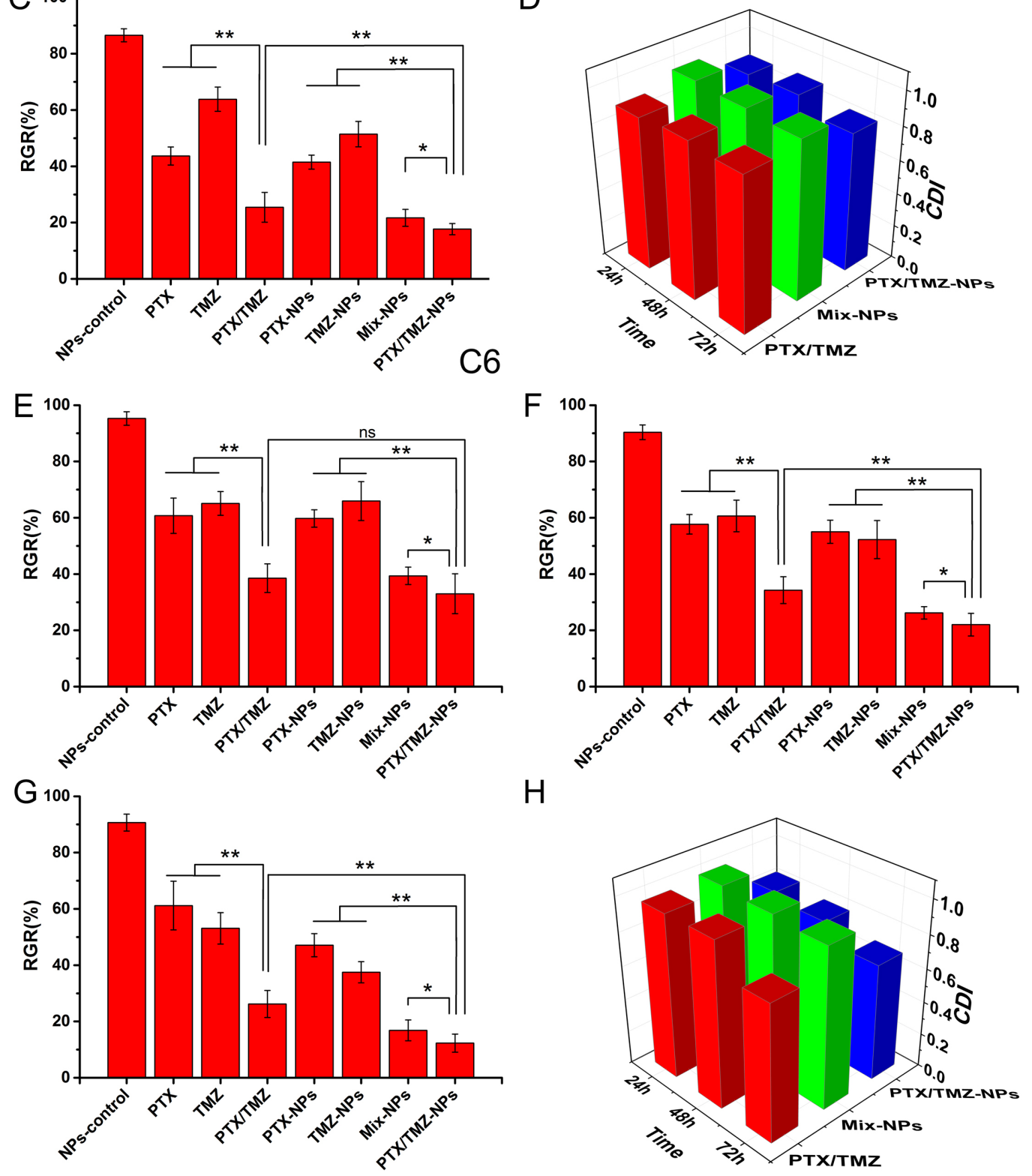

Figure 4: The synergistic inhibitory effects of PTX and TMZ co-loaded in mPEG-PLGA NPs on U87 cells and C6 cells. U87 cells treated with PTX/TMZ-NPs and other comparative formulations for $24 \mathrm{~h} \mathrm{A.} 48 \mathrm{~h} \mathrm{B.} 72 \mathrm{~h} \mathrm{C}$. and CDI values of the combination groups D. C6 cells treated with PTX/TMZ-NPs and other comparative formulations for $24 \mathrm{~h} \mathrm{E.} 48 \mathrm{~h}$ F. $72 \mathrm{~h} \mathrm{G}$. CDI values of the combination groups for $\mathrm{C} 6$ cells $\mathbf{H}$. Data are presented as mean \pm S.D. (error bar) of triplicate cultures. ${ }^{*} \mathrm{P}<0.05,{ }^{*} \mathrm{P}<0.01$, ns $\mathrm{P}>0.05$. 

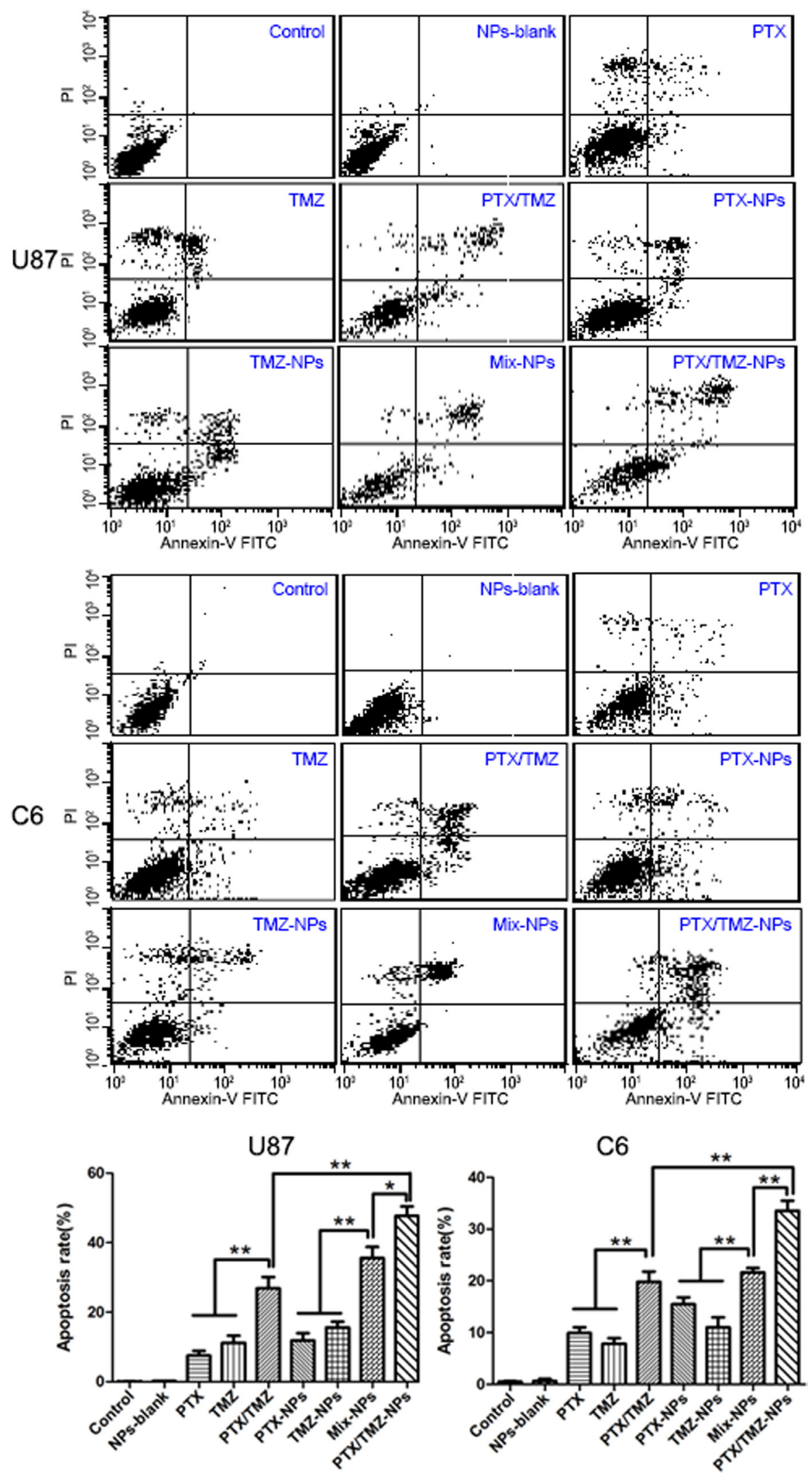

Figure 5: Flow cytometer analysis on cell apoptosis of $\mathrm{U} 87$ cells and $\mathrm{C} 6$ cells incubated $48 \mathrm{~h}$ with different formulations. The PTX, PTX-NPs or PTX/TMZ-NPs solutions were at an equivalent concentration of $4 \mathrm{mg} / \mathrm{L}$ and $0.05 \mathrm{mg} / \mathrm{L}$ PTX for U87 cells and C6 cells, respectively; and the TMZ, TMZ-NPs or PTX/TMZ-NPs at an equivalent concentration of $20 \mathrm{mg} / \mathrm{L}$ and $5 \mathrm{mg} / \mathrm{L}$ TMZ respectively. Data are represented as mean \pm S.D. $(\mathrm{n}=3)$. $* \mathrm{P}<0.05,{ }^{*} * \mathrm{P}<0.01$. 
The coefficient of drug interaction (CDI) was used to analyze the synergistically inhibitory effect of drug combinations. The CDI values less than, equal to or greater than 1 demonstrates that the drugs are synergistic, additive or antagonistic, respectively. Particularly, CDI values less than 0.7 indicate the agents are significantly synergistic [27-29]. A PTX thermo gel depot with TMZ and radiotherapy was reported on gliosarcoma in vivo [30]. But the CDI was not calculated. PTX and TMZ were reported to be co-loaded microsphere on C6 cells in vitro [31]. The optimal weight ratio was $1: 1$. While in our research the optimal ratio was 1:100 on C6 cells. The difference might be because of the different drug release rate in nanoparticles and microsphere.

Based on the synergic of the free drugs, we designed the co-loaded NPs. TMZ is water soluble while PTX is fat soluble. So we designed a hydrophobic shell with the PLGA block to capsulate PTX and the aqueous internal cavities to capsulate TMZ. The mPEG block provided hydrophilic outer shell for EPR effect. The two drugs were loaded in different positions of the NPs and their capsulation did not decrease than single-loaded.

The synergic relationship was observed not only between drug solutions, but also in co-loaded NPs, singleloaded and their mixture $(\mathrm{P}<0.05)$. At $24 \mathrm{~h}$, the superiority of NPs was not obvious. But after $48 \mathrm{~h}$, co-loaded NPs showed better inhibition effect than the mixed solution. This may be because of the sustained release of the NPs so that the drug concentration in cells rose more slowly in NPs groups than in the solution group. But this sustained release maintained drug concentration in cells for a longer time to get better inhibition effect. The co-loaded NPs showed better effect than single-loaded NPs mixture. We supposed this may be because the single-loaded NPs amount was larger than the co-loaded NPs at the same drug concentrations. The cell uptake and efflux is a reversible process in equilibrium. Thus the large amount tends to be transported more, so that the drugs in cells were not equal to the co-loaded NPs group. The detail reasons will be researched in our future work.

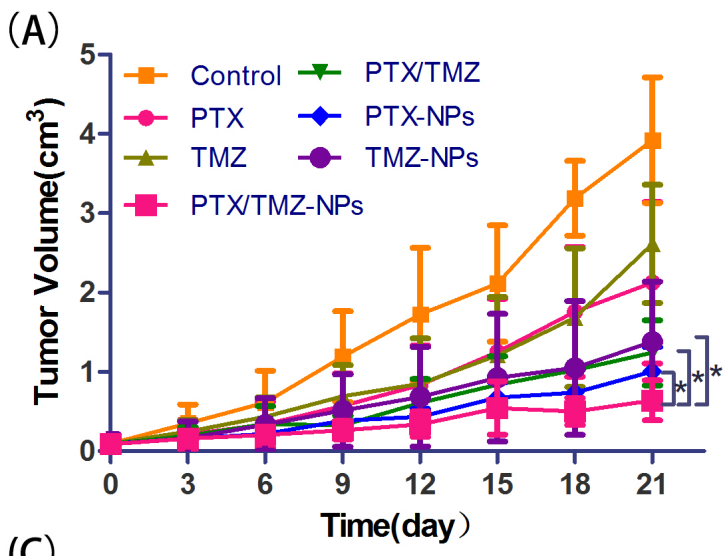

(C)

(D)

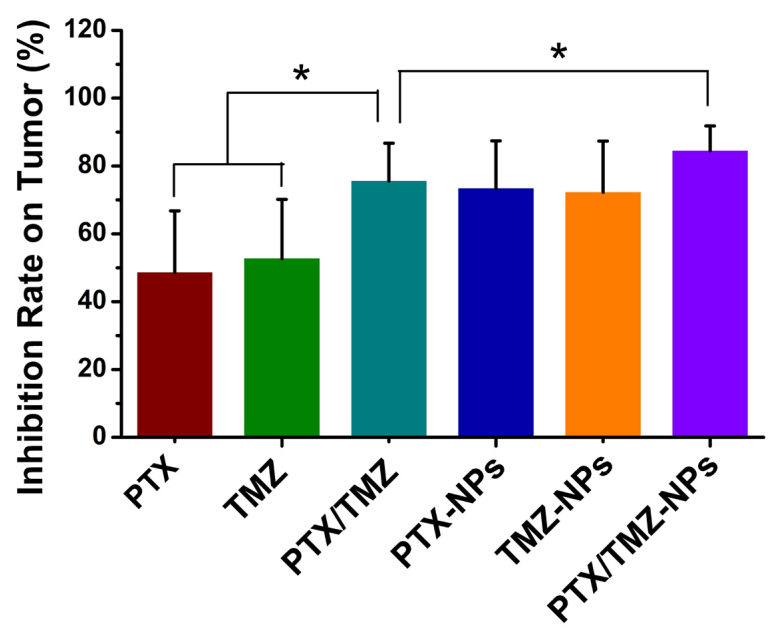

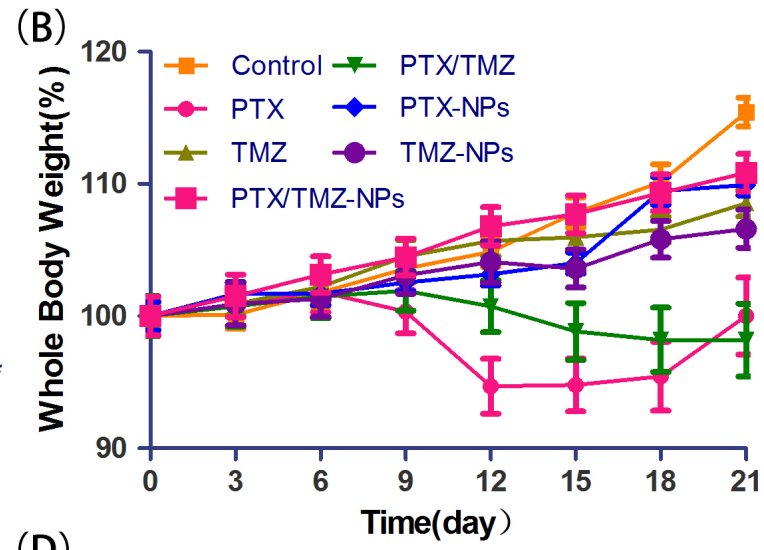

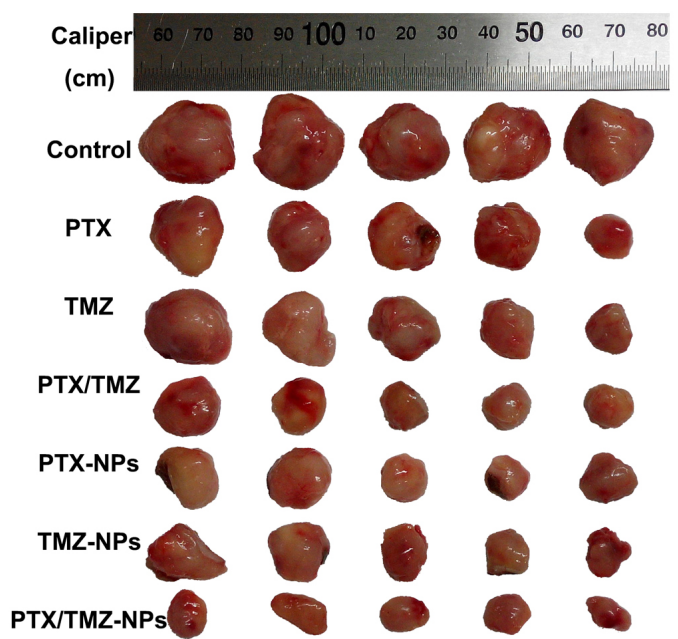

Figure 6: The anti-tumor efficacy of PTX/TMZ-NPs on nude mice bearing U87 xenograft glioblastoma at the experiment terminal $(\mathbf{n}=\mathbf{5})$. A. Tumor growth curves; mean \pm SD. Significant differences found between the PTX/TMZ or PTX-NPs or TMZ-NPs and the PTX/TMZ-NPs groups, and labeled with *p $<0.05$. B. Whole body weight; mean $\pm \mathrm{SD}$. C. Inhibition rate on tumors. D. Tumor xenografts alignment of each group taken out from the sacrificed mice at the study end point. ${ }^{*} \mathrm{P}<0.05$. 
The mPEG block set up hydrophilic outer shell, which provided long-circulation character and enhanced NPs distribution in tumor site in vivo than the solution group [32, 33]. The sustained release characteristic of nanoparticles is essential not only for improving anticancer efficacy but also for reducing adverse-effects. PTX/ TMZ-NPs would be a promising device for the long-term delivery of glioblastoma therapy.

\section{MATERIALS AND METHODS}

\section{Materials}

The 3-(4, 5-dimethylthiazol-2-yl)-2, 5-diphenyltetrazolium bromide (MTT) was purchased from Shanghai qcbio Science \&Technologies co., Ltd.. Dimethyl sulfoxide (DMSO) and Pluronic F-68 (F-68) were purchased from Sigma-Aldrich (USA). Annexin V-FITC Apoptosis Detection Kit was obtained from Beyotime Institute of Biotechnology (Jiangsu, China). Monomethoxy (polyethylene glycol) - poly (D, L -lactideco -glycolide) (mPEG-PLGA) (Mw=15140, mPEG $\mathrm{Mw}=5000,20 \%$, LA: GA 8:2) was synthesized in our laboratory [34]. Paclitaxel (PTX) and Temozolomide (TMZ) standard were from National Institutes for Food and Drug Control. PTX bulk drug was from Jiangsu YEW Biotechnology CO., Ltd (China). TMZ bulk drug was from Dalian Meilun Biotech Co., Ltd (China). Other reagents and solvents (AR grade) were purchased from Sinopharm Chemical Reagent Co., Ltd (China).

\section{Animals and cell lines}

Female BALB/c nude mice (18 $\pm 2 \mathrm{~g})$ were obtained from Shanghai SLRC Laboratory Animal Co., Ltd (China). C6 rat glioma cell line and the human malignant glioblastoma cell line U87 were purchased from Cell Bank of Chinese Academy of Sciences (Shanghai, China). All cell culture reagents were purchased from GIBIC Corporation (CA, USA).

\section{Nanoparticle preparations}

The PTX-NPs were prepared using an emulsion solvent evaporation method $[35,36]$. Briefly, 10mg mPEGPLGA was dissolved in $500 \mu \mathrm{L}$ of PTX dichloromethane solution (PTX $0.2 \mathrm{mg} / \mathrm{mL}$ ). The mixture was added into $5 \mathrm{ml} \mathrm{0.5 \%} \mathrm{F-68} \mathrm{solution} \mathrm{and} \mathrm{emulsified} \mathrm{for} 120 \mathrm{~s}(2 \mathrm{~s}-2 \mathrm{~s}-$ $300 \mathrm{w}$ ) by an ultrasonic processor (JY92-2D Ultrasonic cell crusher, Ningbo SCIENTZ biotechnical Co., Ltd). Then the emulsion was stirred at room temperature to remove the dichloromethane. The nanoparticles were then collected and freeze-dried for subsequent use.

A double emulsification solvent evaporation technique was used to prepare the TMZ-NPs [36, 37].
TMZ was dissolved in $80 \mathrm{uL}$ of $0.1 \mathrm{M} \mathrm{HCl}(4.4 \mathrm{mg} / \mathrm{mL})$ and added into $700 \mu \mathrm{L}$ dichloromethane containing $7 \mathrm{mg}$ mPEG-PLGA. The mixture was emulsified for $120 \mathrm{~s}$ $(2 s-2 s-300 w)$ with an ultrasonic processor. Then the initial emulsion was poured into $5 \mathrm{ml}$ 1\% F-68 solution quickly and emulsified again. The emulsion was then stirred at room temperature to remove the dichloromethane. The nanoparticles were then collected and freeze-dried for subsequent use.

The PTX/TMZ-NPs were prepared with the same double emulsion solvent evaporation method with the TMZ-NPs. TMZ solution $(4.4 \mathrm{mg} / \mathrm{mL}) 80 \mu \mathrm{L}$ was added into $700 \mu \mathrm{L}$ dichloromethane containing $7 \mathrm{mg} \mathrm{mPEG}-$ PLGA and PTX $(0.1 \mathrm{mg} / \mathrm{mL})$. Then the mixture was emulsified and poured into $5 \mathrm{ml} \mathrm{1 \%} \mathrm{F-68} \mathrm{solution} \mathrm{and}$ emulsified again. The dichloromethane was removed by stirred. The nanoparticles were then collected and freezedried for subsequent use.

\section{Characterization of nanoparticles}

The size distribution and average diameters of PTX/TMZ-NPs were analyzed by Zetasizer IV analyzer (Malvern Zetasizer Nano ZS90, UK). The morphology was observed with Transmission electron microscopy (TEM) (H-800; Hitachi, Japan).

The concentration of PTX was determined by HPLC (Agilent 1200, USA) with a $\mathrm{C}_{18}$ chromatographic column (Zorbax SB-C ${ }_{18}, 150 \times 4.6 \mathrm{~mm}, 5 \mu \mathrm{m}$ ). The mobile phase was acetonitrile: $10 \mathrm{mmol} / \mathrm{L} \mathrm{NH}_{4} \mathrm{Ac}$ solution $(\mathrm{pH}=5.0) 53: 47$ at a flow rate of $1.0 \mathrm{~mL} / \mathrm{min}$ and the detection wavelength was $227 \mathrm{~nm}$ [38, 39]. The TMZ was monitored at a wavelength of $328 \mathrm{~nm}$ using an ultraviolet spectrophotometer (UV9000, AoYi Instrument Co., Ltd.) [20]. The free PTX was separated by centrifuge $(5000 \mathrm{r} / \mathrm{min} \times 5 \mathrm{~min})$ and the precipitate was removed. The free TMZ was separated by ultracentrifugation $(\mathrm{MWCO}=10 \mathrm{kDa})$ and the solution was collected as free TMZ. The encapsulation efficiency (EE) and Drug Loading rate (DL) were calculated as follows:

$$
\begin{gathered}
\text { EE }(\%)=\left(\frac{\text { weight of the drug in nanoparticles }}{\text { weight of the feeding drug }}\right) \times 100 \% \\
\text { DL }(\%)=\frac{\text { weight of the feeding drug }}{\text { weight of the nanoparticles }} \times 100 \% \\
\text { In vitro release study was investigated at }
\end{gathered}
$$
$37^{\circ} \mathrm{C}$ in PBS buffer $(\mathrm{pH} 7.4$, with $1 \mathrm{~mol} / \mathrm{L}$ sodium salicylate). Nanoparticles were suspended to $1 \mathrm{~mL}$ and dialyzed against $19 \mathrm{~mL}$ PBS using a dialysis tube $(\mathrm{MWCO}=3.5 \mathrm{kDa})$ with shaking at $80 \mathrm{rpm}$. At preset times, $200 \mu \mathrm{L}$ of dialyzed solution were collected and the same volume of fresh buffer was added. PTX or TMZ concentrations were determined as described above. 


\section{Synergic inhibition of PTX and TMZ on U87 cells and $\mathrm{C} 6$ cells}

C6 cells and U87 cells were cultured in DMEM medium (GIBCO) supplemented with $10 \%(\mathrm{v} / \mathrm{v})$ heat-inactivated fetal bovine serum (FBS) and $1 \%$ antibiotic solution (penicillin $100 \mathrm{U} / \mathrm{mL}$ and streptomycin $100 \mu \mathrm{g} / \mathrm{mL}$ ) at $37^{\circ} \mathrm{C}$ in a humidified atmosphere of $95 \%$ air $/ 5 \% \mathrm{CO}_{2}$.

U87 cells and C6 cells were seeded in 96-well plates and cultured overnight. The medium was replaced with a series of concentrations of PTX $(0.1,0.25,0.5,1,2.5$, $5,7.5,10,15,25,40,50 \mathrm{mg} / \mathrm{L})$ or TMZ $(1,2.5,5,10$, $25,50,75,150,300,600,1200,1500 \mathrm{mg} / \mathrm{L}$ ) respectively. After further cultured for 24/48/72 hours, the medium was changed with fresh DMEM with MTT $(0.5 \mathrm{mg} / \mathrm{mL})$ for another $4 \mathrm{~h}$. The resulting formazan was dissolved in 200 $\mu \mathrm{L}$ of DMSO and detected at $490 \mathrm{~nm}$ using a Microplate Reader (Bio-Rad Laboratories Inc, Hercules, CA, USA). The relative growth rate of the cells (RGR \%) was determined by the following equation:

$$
\text { RGR }(\%)=\frac{\text { OD }(\text { sample })-0 \mathrm{D}(\text { blank })}{\text { OD }(\text { control })-\text { OD }(\text { blank })} \times 100 \%
$$

$\mathrm{IC}_{50}$ values (the median inhibitory concentration) were obtained.

Based on the $\mathrm{IC}_{50}$ values, U87 cells and C6 cells were treated with PTX, TMZ, PTX plus TMZ (PTX/ TMZ) or a control solution. CDI is calculated as follows: $\mathrm{CDI}=\mathrm{AB} /(\mathrm{A} \times \mathrm{B})$. The $\mathrm{AB}$ represents the RGR of the combination group. The $\mathrm{A}$ and $\mathrm{B}$ are the RGR of the single agent groups.

\section{Combined inhibitory and apoptosis-inducing effects of PTX and TMZ loaded in nanoparticles on $\mathrm{U} 87$ cells and c6 cells}

U87 cells and C6 cells were plated in 12-well plates respectively and cultured overnight. The medium in the wells were refreshed and PTX or TMZ preparations were added in for $48 \mathrm{~h}$. Then, the wells were divided into two parts. One part was changed with fresh DMEM with MTT and detected as above. The other wells were treated under instructions of apoptosis detection Kit (Annexin V-FITC, Byotime Co., Ltd.) and detected with a flow cytometry. The treatments were performed in triplicate, and the percentage of labeled cells undergoing apoptosis in each group was determined and calculated.

\section{In vivo antitumor activity}

A U87 cell xenografts model was set up on nude mice by injecting suspension of U87 cells $\left(5 \times 10^{6}\right.$ cells in $0.2 \mathrm{~mL}$ of saline) subcutaneously. When the tumors were about $90 \pm 10 \mathrm{~mm}^{3}$, the mice (female, $18 \pm 2 \mathrm{~g}$ ) were randomly divided into seven groups $(n=5)$ and intravenously administered respectively with $200 \mu \mathrm{L}$ of saline, PTX, TMZ, PTX/TMZ, PTX-NPs, TMZ-NPs or PTX/TMZ-NPs, at the dose of PTX $4 \mathrm{mg} / \mathrm{kg}[40,43]$ and TMZ $20 \mathrm{mg} / \mathrm{kg}$ [44]. The treatments were repeated every two days. Tumor size was used to assess the efficacy of therapy. Two perpendicular diameters were measured with a caliper every three days until the mice were sacrificed. The tumor volume $(\mathrm{V})$ was calculated as:

$$
\mathrm{V}\left(\mathrm{mm}^{3}\right)=\frac{\text { length } \times(\text { width })^{2}}{2}
$$

Meanwhile, the whole body weight was simultaneously monitored as an evaluation of toxicity.

\section{Data analysis}

Data were generated in multiples of triplicates for proper statistical analysis. Analysis of variance (ANOVA) was used within each treatment and applied among the groups. Results were expressed as mean \pm standard deviation (SD). A probability (P) less than 0.05 was considered statistically significant.

\section{ACKNOWLEDGMENTS}

This research was supported by the National Natural Science Foundation of China (No. 81272568, 81301973, 81502692 and 51372084), the Nature Science Foundation of Shanghai (No. 13ZR1440200 and 15ZR1439100), the basic project of Science and Technology Commission of Shanghai Municipality (No.14JC1492500), foundation of Shanghai Municipal Commission of Health \& Family Planning (No. 201440015), the medical guide project of Science and Technology Commission of Shanghai Municipality (No.134119a1300) and Shanghai Cancer Institute Foudation (No. SB1504).

\section{CONFLICTS OF INTEREST}

There are no conflicts of interest.

\section{REFERENCES}

1. Siegel R, Naishadham D, Jemal A. Cancer statistics, 2013. CA-a Cancer Journal for Clinicians. 2013; 63:11-30.

2. Mason WP, Cairncross JG. Drug Insight: temozolomide as a treatment for malignant glioma-impact of a recent trial. Nature Clinical Practice Neurology. 2005; 1:88-95.

3. Bidros DS, Vogelbaum MA. Novel drug delivery strategies in neuro-oncology. Neurotherapeutics. 2009; 6:539-546.

4. Arko L, Katsyv I, Park GE, Luan WP, Park JK. Experimental approaches for the treatment of malignant gliomas. Pharmacology \& Therapeutics. 2010; 128:1-36.

5. Dong J, Zhou GH, Tang DF, Chen YM, Cui BQ, Dai XL, Zhang ZS, Lan Q and Huang Q. Local delivery 
of slow-releasing temozolomide microspheres inhibits intracranial xenograft glioblastoma growth. Journal of Cancer Research and Clinical Oncology. 2012; 138: 2079-2084

6. Stupp R, Hegi M, Weller M. Neuro-oncology, a decade of temozolomide and beyond. Expert Review of Anticancer Therapy. 2010; 10:1675-1677.

7. Li XQ, Ouyang ZG, Zhang SH, Liu H, Shang Y, Li Y, Zhen YS. Synergy of enediyne antibiotic lidamycin and temozolomide in suppressing glioblastoma growth with potentiated apoptosis induction. Journal of NeuroOncology. 2014; 119:91-100.

8. Johnson DR, O'Neill BP. Glioblastoma survival in the United States before and during the temozolomide era. Journal of Neuro-Oncology. 2012; 107:359-364.

9. Sasai K, Nodagashira M, Nishihara H, Aoyanagi E, Wang L, Katoh M, Murata J, Ozaki Y, Ito T, Fujimoto S, Kaneko S, Nagashima K, Tanaka S. Careful exclusion of nonneoplastic brain components is required for an appropriate evaluation of O6-methylguanine-DNA methyltransferase status in glioblastoma: relationship between immunohistochemistry and methylation analysis. American Journal of Surgical Pathology. 2008; 32:1220-1227.

10. Hegi ME, Diserens A, Gorlia T, Hamou M, de Tribolet N, Weller M, Kros JM, Hainfellner JA, Mason W, Mariani L, Bromberg JEC, Hau P, Mirimanoff RO, Cairncross JG, Janzer RC, Stupp R. MGMT gene silencing and benefit from temozolomide in glioblastoma. New England Journal of Medicine. 2005; 352:997-1003.

11. Paz MF, Yaya-Tur R, Rojas-Marcos I, Reynes G, Pollan M, Aguirre-Cruz L, Garcia-Lopez JL, Piquer J, Safont MJ, Balana C, Sanchez-Cespedes M, Garcia-Villanueva M, Arribas L, Esteller M. CpG island hypermethylation of the DNA repair enzyme methyltransferase predicts response to temozolomide in primary gliomas. Clinical Cancer Research. 2004; 10:4933-4938.

12. Santoni M, Paccapelo A, Burattini L, Onofri A, Cascinu S. Twice-daily dosing of temozolomide in combination with fotemustine for the treatment of patients with refractory glioblastoma. Anticancer Research. 2012; 32:1099-1101.

13. Rivkin I, Cohen K, Koffler J, Melikhov D, Peer D, Margalit R. Paclitaxel-clusters coated with hyaluronan as selective tumor-targeted nanovectors. Biomaterials. 2010; 31:7106-7114.

14. Marupudi NI, Han JE, Li KW, Renard VM, Tyler BM, Brem H. Paclitaxel: a review of adverse toxicities and novel delivery strategies. Expert Opinion on Drug Safety. 2007; 6:609-621.

15. Fruehauf JP, Brem H, Brem S, Sloan A, Barger G, Huang $\mathrm{W}$, Parker R. In vitro drug response and molecular markers associated with drug resistance in malignant glioblastomas. Clinical Cancer Research. 2006; 12:4523-4532.

16. Fung LK, Ewend MG, Sills A, Sipos EP, Thompson R, Watts M, Colvin OM, Brem H, Saltzman WM.
Pharmacokinetics of interstitial delivery of carmustine, 4-hydroperoxycyclophosphamide, and paclitaxel from a biodegradable polymer implant in the monkey brain. Cancer Research. 1998; 58:672-684.

17. Arifin DY, Lee KYT, Wang C-H. Chemotherapeutic drug transport to brain tumor. Journal of Controlled Release. 2009; 137:203-210.

18. Azzabi A, Hughes AN, Calvert PM, Plummer ER, Todd R, Griffin MJ, Lind MJ, Maraveyas A, Kelly C, Fishwick K, Calvert AH, Boddy AV. Phase I study of temozolomide plus paclitaxel in patients with advanced malignant melanoma and associated in vitro investigations. British Journal of Cancer. 2005; 92:1006-1012.

19. Ni S, Fan X, Wang J, Qi H, Li X. Biodegradable implants efficiently deliver combination of paclitaxel and temozolomide to glioblastoma C6 cancer cells in vitro. Annals of Biomedical Engineering. 2014; 42:214-221.

20. Konno T, Watanabe J, Ishihara K. Enhanced solubility of paclitaxel using water-soluble and biocompatible 2-methacryloyloxyethyl phosphorylcholine polymers. Journal of Biomedical Materials Research Part A. 2003; 65:209-214.

21. Ling Y, Wei K, Zou F, Zhong S. Temozolomide loaded PLGA-based superparamagnetic nanoparticles for magnetic resonance imaging and treatment of malignant glioblastoma. International Journal of Pharmaceutics. 2012; 430:266-275.

22. Guo JW, Gao XL, Su LN, Xia HM, Gu GZ, Pang ZQ, Jiang XG, Yao L, Chen J, Chen HZ. Aptamer-functionalized PEG-PLGA nanoparticles for enhanced anti-glioblastoma drug delivery. Biomaterials. 2011; 32:8010-8020.

23. Grottkau BE, Cai X, Wang J, Yang X, Lin Y. Polymeric Nanoparticles for a Drug Delivery System. Current Drug Metabolism. 2013; 14:840-846.

24. Zhu D, Lu X, Hardy PA, Leggas M, Jay M. Nanotemplateengineered nanoparticles containing gadolinium for magnetic resonance imaging of tumors. Investigative Radiology. 2008; 43:129-140.

25. Brigger I, Dubernet C, Couvreur P. Nanoparticles in cancer therapy and diagnosis. Advanced Drug Delivery Reviews. 2002; 54:631-651.

26. Maeda H, Wu J, Sawa T, Matsumura Y, Hori K. Tumor vascular permeability and the EPR effect in macromolecular therapeutics: a review. Journal of Controlled Release. 2000; 65:271-84.

27. Chen $\mathrm{CH}$, Chen MC, Wang JC, Tsai AC, Chen CS, Liou JP, Pan SL, Teng CM. Synergistic interaction between the HDAC inhibitor, MPT0E028, and sorafenib in liver cancer cells in vitro and in vivo. Clinical Cancer Research. 2014; 20:1274-1287.

28. Qiu B, Sun X, Zhang D, Wang Y, Tao J, Ou S. TRAIL and paclitaxel synergize to kill U87 cells and U87-derived stem-like cells in vitro. International Journal of Molecular Sciences. 2012; 13:9142-9156. 
29. Wan XA, Sun GP, Wang H, Xu SP, Wang ZG, Liu SH. Synergistic effect of paeonol and cisplatin on oesophageal cancer cell lines. Digestive and Liver Disease. 2008; 40:531-539.

30. Vellimana AK, Recinos VR, Hwang L, Fowers KD, Li KW, Zhang YG, Okonma S, Eberhart CG, Brem H, Tyler BM. Combination of paclitaxel thermal gel depot with temozolomide and radiotherapy significantly prolongs survival in an experimental rodent glioma model. Journal of Neuro-Oncology. 2013; 111:229-236.

31. Ni SL, Fan XY, Wang JG, Qi HX, Li XG. Biodegradable implants efficiently deliver combination of paclitaxel and temozolomide to glioma c6 cancer cells in vitro. Annals of Biomedical Engineering. 2014; 42:214-221.

32. Lv W, Cheng L, Li B. development and evaluation of a novel tpgs-mediated paclitaxel-loaded plgampeg nanoparticle for the treatment of ovarian cancer. Pharmaceutical Bulletin. 2015; 63:68-74.

33. Avgoustakis K, Beletsi A, Panagi Z, Klepetsanis P, Karydas AG, Ithakissios DS. PLGA-mPEG nanoparticles of cisplatin: in vitro nanoparticle degradation, in vitro drug release and in vivo drug residence in blood properties. Journal of Controlled Release. 2002; 79:123-135.

34. Liu P, Yu H, Sun Y, Zhu M, Duan Y. A mPEG-PLGA-bPLL copolymer carrier for adriamycin and siRNA delivery. Biomaterials. 2012; 33:4403-4412.

35. Ali ME, Lamprecht A. Polyethylene glycol as an alternative polymer solvent for nanoparticle preparation. International Journal of Pharmaceutics. 2013; 456:135-142.

36. Xu YY, Shen M, Sun Y, Gao P, Duan YR. Polymer nanocomposites based thermo-sensitive gel for paclitaxel and temozolomide co-delivery to glioblastoma cells. Journal of Nanoscience and Nanotechnology. 2015; 15:9777-9787. doi: 10.1166/jnn.2016.12338.

37. Wu G, Chen L, Li H, Wang Y-j. Hyaluronic acid as an internal phase additive to obtain ofloxacin/PLGA microsphere by double emulsion method. Bio-Medical Materials and Engineering. 2014; 24:751-756.
38. Ranganath SH, Fu YL, Arifin DY, Kee I, Zheng L, Lee HS, Chow PKH, Wang $\mathrm{CH}$. The use of submicron/nanoscale PLGA implants to deliver paclitaxel with enhanced pharmacokinetics and therapeutic efficacy in intracranial glioblastoma in mice. Biomaterials. 2010; 31:5199-5207.

39. Kim SC, Yu J, Lee JW, Park ES, Chi SC. Sensitive HPLC method for quantitation of paclitaxel Genexol in biological samples with application to preclinical pharmacokinetics and biodistribution. Journal of Pharmaceutical and Biomedical Analysis. 2005; 39:170-176.

40. Xin H, Chen L, Gu J, Ren X, Wei Z, Luo J, Chen Y, Jiang X, Sha X, Fang X. Enhanced anti-glioblastoma efficacy by PTX-loaded PEGylated poly( $\varepsilon$-caprolactone) nanoparticles: In vitro and in vivo evaluation. International Journal of Pharmaceutics. 2010; 402:238-47.

41. Guan DG, Chen HM, Liao SF, Zhao TZ. Combination of temozolomide and Taxol exerts a synergistic inhibitory effect on Taxol-resistant glioma cells via inhibition of glucose metabolism. Molecular Medicine Reports. 2015; 12: $7705-11$.

42. Ott PA, Chang J, Madden K, Kannan R, Muren C, Escano C, Cheng X, Shao YZ, Mendoza S, Gandhi A, Liebes L, Pavlick AC. Oblimersen in combination with temozolomide and albumin-bound paclitaxel in patients with advanced melanoma: a phase I trial. Cancer Chemotherapy and Pharmacology. 2013; 71: 183-191.

43. Jiang X, Xin H, Sha X, Gu J, Jiang Y, Law K, Chen Y, Chen L, Wang X, Fang X. PEGylated poly(trimethylene carbonate) nanoparticles loaded with paclitaxel for the treatment of advanced glioma: in vitro and in vivo evaluation. International Journal of Pharmaceutics. 2011; 420:385-94.

44. Moroz MA, Huang R, Kochetkov T, Shi W, Thaler H, de Stanchina E, Gamez I, Ryan RP, Blasberg RG. Comparison of corticotropin-releasing factor, dexamethasone, and temozolomide: treatment efficacy and toxicity in U87 and C6 intracranial gliomas. Clinical Cancer Research. 2011; 17:3282-92. 